\title{
Performance evaluation of a multi-branch gas-liquid pipe separator using computational fluid dynamics
}

\author{
H. Refsnes ${ }^{1} \cdot$ M. Diaz ${ }^{1} \cdot$ M. Stanko ${ }^{1}$ \\ Received: 16 October 2018 / Accepted: 30 May 2019 / Published online: 11 June 2019 \\ (c) The Author(s) 2019
}

\begin{abstract}
The present paper aims to evaluate the performance of a multi-branch gas-liquid pipe separator by means of 3D computational fluid dynamics. This type of separator is attractive for deepwater subsea hydrocarbon fields due to its compactness and reduced weight when compared against traditional gravity vessel separators. The focus of this paper is on studying the internal flow dynamics, the separation efficiency, and the performance with changing and transient operating conditions. Numerical simulations were performed on a numerical prototype of the separator using the inhomogeneous mixture model and assuming that both phases are continuous. Sensitivity analyses were performed on gas volume fraction, outlet pressures, and considering slug flow at the inlet with periods of $2 \mathrm{~s}$ and $8 \mathrm{~s}$. The separation efficiency was quantified by calculating the liquid carry-over and gas blowby. For most of the operational conditions studied, separation occurred primarily in pipe branches closer to the inlet while those closer to the outlet exhibited a static liquid level. Reducing the gas outlet pressure caused the height of the liquid in the branches to be reduced. The inlet gas volume fraction did not affect significantly the separation performance, the flow distribution, nor the liquid level inside the separator. Separation efficiencies were not affected significantly with the presence of slugs; however, the liquid level in the branches oscillated significantly. The results and numerical models produced by this study could potentially be used to improve the understanding of this type of separators and improve its efficiency and system-level design.
\end{abstract}

Keywords Gas-liquid separation · Subsea processing · Computational fluid dynamics

\section{List of symbols}

\section{Variables}

$\Delta y \quad$ Thickness of cell closest to wall (m)

$u_{*} \quad$ Friction velocity $(\mathrm{m} / \mathrm{s})$

$t \quad$ Time (s)

$U \quad$ Velocity vector

$U \quad$ Velocity component $(\mathrm{m} / \mathrm{s})$

$p \quad$ Pressure (Pa, bara)

$g \quad$ Gravitational acceleration $\left(\mathrm{m} / \mathrm{s}^{2}\right)$

$M_{\mathrm{p}} \quad$ Momentum interphase $\left(\mathrm{N} / \mathrm{m}^{3}\right)$

$C_{\mathrm{D}} \quad$ Drag coefficient

$d_{\mathrm{og}} \quad$ Oil-gas interfacial length (m)

$\mu_{\mathrm{t}} \quad$ Turbulent viscosity (Pa s)

$k \quad$ Kinetic energy $\left(\mathrm{m}^{2} / \mathrm{s}^{2}\right)$

$p_{k} \quad$ Turbulent production $\left(\mathrm{kg} / \mathrm{m} \mathrm{s}^{3}\right)$

M. Diaz

mariana.j.diaz@ntnu.no

1 Department of Geoscience and Petroleum, Norwegian University of Science and Technology, Trondheim, Norway

\section{Greek symbols}

$\rho \quad$ Density $\left(\mathrm{kg} / \mathrm{m}^{3}\right)$

$\mu \quad$ Dynamic viscosity (Pa s)

$\alpha \quad$ Volume fraction

$\varepsilon \quad$ Turbulent dissipation rate $\left(\mathrm{m}^{2} / \mathrm{s}^{3}\right)$

\section{Subscripts}

$o \quad$ Oil

$g \quad$ Gas

OG Outlet of gas

OL Outlet of liquid

$p \quad$ Generic phase " $p$ "

$j \quad$ Generic spatial coordinate

$i \quad$ Generic spatial coordinate

$m \quad$ Mixture

\section{Superscripts}

$o \quad$ Oil

g Gas

\section{Abbreviations}

CFD Computational fluid dynamics

GCU Gas carry under 
GLCC Gas liquid cylindrical cyclone

GVF Gas volume factor

LCO Liquid carry-over

RSM Reynolds stress model

VOF Volume of fluid

\section{Introduction}

There are challenges when moving processing equipment to subsea, especially in deepwater fields with high hydrostatic pressure. Conventional separator vessels with a large diameter require thick walls; hence, the equipment is heavy and expensive to build and to deploy. Reducing the diameter on separators gives a more compact solution compared to conventional vessels, as they require a thinner wall and can be designed and manufactured using pipe-code guidelines.

For subsea gas-liquid separation, a design available in the market that has been field and laboratory tested is the multibranch pipe separator design called "Harp." The design was patented by Norsk Hydro, currently Equinor (Gramme and Lie 2011), and it consists of a downward inclined pipe with six vertical pipes for gas removal (as shown in Fig. 1). The liquid flows down through the lower horizontal pipe as this is the heavy phase, while the gas rises through the vertical pipes and is further collected and transported toward the outlet through the upper pipe. The vertical pipes can be partially filled with liquid, thus having a spare volume suitable to accommodate for fluctuations in the inlet flows of liquid and gas, e.g., due to slug flow (Sagatun et al. 2008). A small diameter provides short retention time, which makes the separator a compact solution compared to conventional gravity vessels with larger diameters.

A Harp is currently installed subsea as part of the SSAO Marlim system (SSAO is short for Separação Submarina de Água-Óleo in Portuguese, which means Subsea Oil-Water Separation) in the Marlim field in Brazil (Orlowski et al. 2012). Marlim is a brownfield producing with a high water cut (Euphemio et al. 2007). Topside processing and disposing of water are expensive and bottlenecks oil production; hence, a subsea water separation station was implemented. The Harp is placed at a water depth of $876 \mathrm{~m}$ and at the

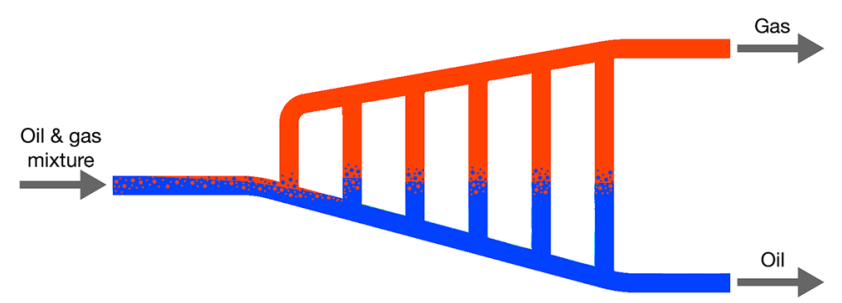

Fig. 1 Schematic drawing of the separator inlet of a pipe separator for oil-water separation, which is designed for a liquid flow rate of $3500 \mathrm{Sm}^{3} /$ day. The water is further processed and reinjected into the formation while the oil and gas are mixed and transported to surface facilities through a 2.4-km-long pipe. The main intention of the Harp is slug catching and bulk separation of gas to allow using a small diameter in the oil-water pipe separator downstream of the liquid outlet.

The Harp multi-branch pipe separator could be used for different applications that require bulk gas or liquid removal, e.g., before gas or liquid boosters. Gas compression systems, for instance, are very sensitive to the liquid content in the gas stream, compromising the equipment performance and reliability. Liquid boosting, on the other hand, can tolerate very high void fraction in the liquid stream, but at expense of efficiency and boosting capability. Gas-liquid separation may enable better operating conditions and allow higher boosting efficiency in both cases. The Harp separator could also be suitable for cases where decentralized subsea processing (at well or cluster level) is desired.

Unfortunately, there is limited information in the literature available to the public about the separation performance of the Harp, especially regarding operational envelope, flow dynamics in the separator, separation efficiency, slug-handling capabilities, etc. This, to the authors' opinion, limits the understanding about the technology and inhibits further implementation, development and improvement in the design.

In this work, a prototype of the Harp separator is studied in detail using two-phase computational fluid dynamics (CFD). The focus is to study the internal flow dynamics, the separation efficiency, and the performance with changing and transient operating conditions. This will hopefully clarify the operating principle of the technology and will serve as a useful reference for future researchers and industry people that wish to improve further or use and deploy this technology. Unfortunately, there are no experimental data available to the public on the performance of this separator to compare the results of the numerical simulations against, which is an important limitation of the present study.

Bulk gas-liquid separation has been studied extensively and successfully in the past by several researchers using computational fluid dynamic simulations. In CFD simulation software, typically the user must specify the topology of the phase beforehand (either continuous or dispersed). This modeling assumption is used further when formulating expressions of the momentum, mass, and energy transfer terms between the phases.

For example, Afolabi and Lee (2014) used the commercial CFD package ANSYS Fluent with the particle model and Reynolds stress turbulence model (RSM) to study air-water flow in a GLCC (Gas-Liquid Cylindrical Cyclone) separator. The air was treated as the dispersed 
phase, characterized by a representative bubble diameter, in a continuous water phase. Phase segregation in a helical pipe was analyzed experimentally and numerically by da Mota and Pagano (2014), using the commercial CFD software ANSYS CFX. The $K$-epsilon turbulence model was used, and the water and gas were treated as dispersed phases (droplet and bubbles) with the oil as the continuous phase. The results of the numerical simulations were in agreement with experimental measurements. Monesi et al. (2013) conducted numerical simulations to evaluate the performance of a slug catcher. Two different models were created in ANSYS CFX for the liquid and the gas-dominated stream. Simulations of the liquid-dominated stream were conducted with the particle model using k-epsilon as turbulence model. The model was able to predict the performance of the slug catcher for the corresponding operating conditions.

Ghaffarkhah et al. (2018) used CFD to model three-phase separation in a horizontal vessel to evaluate different vessel configurations and choosing the best. The volume of fluid (VOF) model was used for the continuous phase and a Lagrangian approach for tracking the movement of droplets and bubbles. The K-epsilon turbulence model was employed. Ghaffarkah et al. (2019) also used CFD to study three-phase separation in a horizontal vessel to determine its optimal dimensions. They used the same simulation settings as Ghaffarkhah et al. (2018), but tested two additional turbulence models, $K$-omega and Reynolds stress. When comparing against experimental data, they concluded that $K$-epsilon provided a better agreement.

\section{Description of numerical simulations}

\section{Geometry}

The geometry of the multi-branch pipe separator used for the numerical simulations was roughly estimated based on pictures and information available in publications about the Harp experimental campaign performed at facilities in Porsgrunn, Norway (Sagatun et al. 2008). This is a reduced scale prototype of the Harp used in the Marlim field. The modeled geometry of the separator shown in Fig. 2 is $4.9 \mathrm{~m}$ long and $2 \mathrm{~m}$ high, with a pipe diameter of $0.1524 \mathrm{~m}$ (6 in.).

\section{Settings of CFD simulations}

The properties of the fluids used in the CFD simulations are shown in Table 1. They are supposed to resemble in situ oil and gas fluid properties in the Marlim field Harp separator. The properties have been calculated using untuned black oil correlations with an operating pressure of 85 bara, temperature $55^{\circ} \mathrm{C}$, GOR of $17.8 \mathrm{Sm}^{3} / \mathrm{Sm}^{3}$, and a $22^{\circ}$ API separator oil (Euphemio et al. 2007). The correlation given

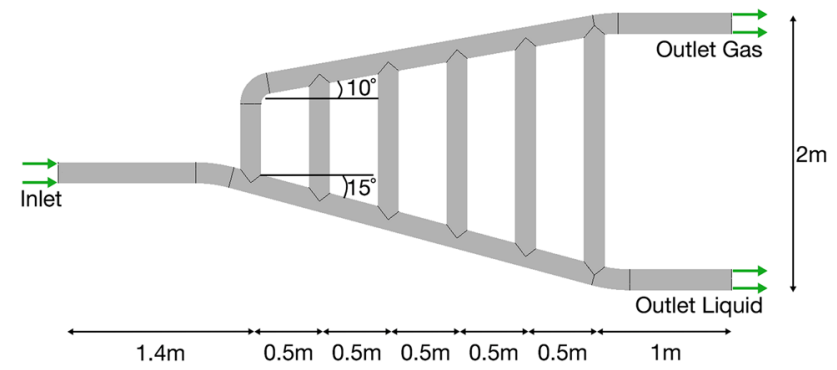

Fig. 2 Separator geometry and location of boundary conditions

Table 1 Oil and gas properties for multiphase simulation

\begin{tabular}{ll}
\hline Parameters & Values \\
\hline$\rho_{\mathrm{o}}\left(\mathrm{kg} / \mathrm{m}^{3}\right)$ & 814 \\
$\mu_{\mathrm{o}}(\mathrm{Pa} \mathrm{s})$ & 0.0095 \\
$\rho_{\mathrm{g}}\left(\mathrm{kg} / \mathrm{m}^{3}\right)$ & 128 \\
$\mu_{\mathrm{g}}(\mathrm{Pa} \mathrm{s})$ & $1.6 \mathrm{E}-5$ \\
\hline
\end{tabular}

by Standing (1947) is used for calculation of solution gas-oil ratio. Correlations by Lee et al. (1966) and Beggs and Robinson (1975) are used for gas and oil viscosity calculations. This resulted in a solution gas-oil ratio of $17.8 \mathrm{Sm}^{3} / \mathrm{Sm}^{3}$. Both fluids have constant properties in the simulation; therefore, gas compressibility, potential oil vaporization, and phase change are neglected. The energy equation and estimation of the temperature distribution are not included in the simulations.

The following boundary conditions were used for the simulations (locations are indicated in Fig. 2): mixture velocity uniform over the cross-sectional area, gas volume fraction (GVF) at the inlet, and average static pressure at the gas and liquid outlets. This combination of boundary conditions was chosen because it resembled more closely the real physical system, where outlet pressures can be controlled by adjusting components (e.g., valves) in the downstream lines of liquid and gas. The wall roughness of the pipe is set to smooth with a no-slip boundary condition. The effect of wall roughness on simulation results has not been evaluated in the present work.

\section{CFD model}

The simulations were carried out using the commercial code ANSYS CFX v17.2. To select the model to employ, four different multiphase models available in the software were evaluated in terms of their capability to represent realistic flow distribution and separation and convergence characteristics. Some models evaluated were:

- Liquid continuous-gas continuous phases and homogeneous mixture: This model employs mixture momentum

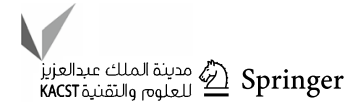


equations with average properties that depend on the volume fraction. It is usually suitable for stratified gravity flow where the interface is clear and in cases where the interface momentum transfer is large.

- Liquid continuous-gas continuous phases, homogeneous mixture and free surface: This model is similar to the previous one, but in addition considers the curvature of the interface using the surface tension and uses it to allocate volume fractions of mesh cells.

- Liquid continuous-gas dispersed phases and inhomogeneous mixture: This model employs separate momentum equations for each phase (i.e., accounts for slip), which makes it more computationally expensive. Interfacial forces considered were: buoyancy, drag, lift, wall lubrication, and turbulent dispersion.

- Liquid continuous-gas continuous phases and inhomogeneous mixture: This model employs separate momentum equations for each phase. Interfacial forces considered were: buoyancy and drag.

The details of the selection process are provided in Refsnes (2018). The continuous-continuous inhomogeneous mixture model was the multiphase model providing the most realistic results and best convergence behavior and was therefore employed for the rest of the analysis.

The Euler-Euler inhomogeneous model consists of two separate momentum and mass conservation equations for the oil and the gas. Both phases are considered continuous. For a generic phase " $p$," neglecting mass transfer, the momentum conservation equation is:

$$
\begin{aligned}
& \frac{\partial\left(\rho_{\mathrm{p}} \cdot U_{\mathrm{p}} \cdot \alpha_{\mathrm{p}}\right)}{\partial t}+\nabla \cdot\left[\alpha_{\mathrm{p}} \cdot\left(\rho_{\mathrm{p}} \cdot U_{\mathrm{p}} \cdot U_{\mathrm{p}}\right)\right] \\
& \quad=-\alpha_{\mathrm{p}} \cdot \nabla p+\nabla \cdot\left[\alpha_{\mathrm{p}} \cdot \mu_{\mathrm{p}} \cdot\left(\nabla U_{\mathrm{p}}+\left(\nabla U_{\mathrm{p}}\right)^{T}\right)\right] \\
& \quad+\alpha_{\mathrm{p}} \cdot \rho_{\mathrm{p}} \cdot g+M_{\mathrm{p}}
\end{aligned}
$$

The momentum interphase term $\left(M_{\mathrm{p}}\right)$, in the case of oil, is calculated by:

$M_{\mathrm{o}}=C_{\mathrm{D}} \cdot \rho_{\mathrm{m}} \cdot\left(\frac{\alpha_{\mathrm{o}} \cdot \alpha_{\mathrm{g}}}{d_{\mathrm{og}}}\right) \cdot\left(U_{\mathrm{g}}-U_{\mathrm{o}}\right) \cdot\left|U_{\mathrm{g}}-U_{\mathrm{o}}\right|$

The momentum interphase term for gas is the same as for oil, but with opposite sign.

The interfacial length $d_{\mathrm{og}}$ is given as an input (in this work, it was assumed $d_{\mathrm{og}}=1 \mathrm{~mm}$ ). The drag coefficient is, assuming fully turbulent flow, $C_{\mathrm{D}}=0.44$.

The mixture density is $\rho_{\mathrm{m}}=\alpha_{\mathrm{o}} \cdot \rho_{\mathrm{o}}+\alpha_{\mathrm{g}} \cdot \rho_{\mathrm{g}}$. The mixture viscosity $\left(\mu_{\mathrm{m}}\right)$ is written in a similar fashion.
The mass conservation equation for all phases, considering incompressible flow, can be reduced to:

$\sum_{\mathrm{p}} \nabla \cdot\left(U_{\mathrm{p}} \cdot \alpha_{\mathrm{p}}\right)=0$

The Reynolds-averaged Navier-Stokes $K$-epsilon model was used to model turbulence. In this model, there are two additional conservation equations: one for the turbulent kinetic energy $k$ and one for the turbulent dissipation rate $\varepsilon$ :

$\frac{\partial\left(\rho_{\mathrm{m}} \cdot k\right)}{\partial t}+\frac{\partial}{\partial x_{i}}\left(U_{i} \cdot \rho_{\mathrm{m}} \cdot k\right)=\frac{\partial}{\partial x_{j}}\left[\left(\frac{\mu_{\mathrm{t}}}{\sigma_{\mathrm{k}}}+\mu_{\mathrm{m}}\right) \frac{\partial k}{\partial x_{j}}\right]-\rho_{\mathrm{m}} \cdot \varepsilon+p_{\mathrm{k}}$

$$
\begin{gathered}
\frac{\partial\left(\rho_{\mathrm{m}} \cdot \varepsilon\right)}{\partial t}+\frac{\partial}{\partial x_{i}}\left(U_{i} \cdot \rho_{\mathrm{m}} \cdot \varepsilon\right)=\frac{\partial}{\partial x_{j}}\left[\left(\frac{\mu_{\mathrm{t}}}{\sigma_{\varepsilon}}+\mu_{\mathrm{m}}\right) \frac{\partial \varepsilon}{\partial x_{j}}\right] \\
+\frac{\varepsilon}{k} \cdot\left(C_{\varepsilon 1} \cdot p_{k}-C_{\varepsilon 2} \cdot \rho_{\mathrm{m}} \cdot \varepsilon\right)
\end{gathered}
$$

In these equations, $C_{\varepsilon 1}=1.44, C_{\varepsilon 2}=1.92, \sigma_{k}=1$, and $\sigma_{\varepsilon}=1.3 . \mu_{t}$ is the turbulent viscosity:

$\mu_{\mathrm{t}}=C_{\mu} \cdot \rho_{\mathrm{m}} \cdot \frac{k^{2}}{\varepsilon}$

where $C_{\mu}=0.09 . p_{\mathrm{k}}$ is the turbulence production due to viscous forces:

$p_{\mathrm{k}}=\mu_{\mathrm{t}} \cdot\left(\frac{\partial U_{i}}{\partial x_{j}}+\frac{\partial U_{j}}{\partial x_{i}}\right) \cdot \frac{\partial U_{j}}{\partial x_{j}}$

The software employs an element-based finite volume method to solve the conservation equations. Control volumes are constructed around each mesh node. The value of variables and gradients of variables of the element are approximated with a finite-element shape function (that depends on the type of element) that makes a weighted sum of all nodes within an element. The conservation equations are integrated over each control volume, and Gauss' divergence theorem is used to convert integrals of volume to surface integrals. In this work, the advection terms were modeled with highresolution scheme, which uses a blend factor to combine upwind and second-order differencing schemes. The blend factor is estimated at each node trying for it to be as close to 1 based on the principles discussed by Barth and Jesperson (1989). The transient term was discretized with a secondorder backward Euler stencil.

\section{Mesh validation}

A mesh independence study under single-phase flow conditions (water) was performed to find a mesh which provides accurate results with the minimum possible 
Table 2 Main properties and characteristics of the meshes employed

\begin{tabular}{llllllll}
\hline Mesh Nr. & Nr. nodes (k) & $\begin{array}{l}\text { Maximum } \\
\text { aspect ratio }\end{array}$ & $\begin{array}{l}\text { Maximum ortho } \\
\text { skew (Fluent) }\end{array}$ & \multicolumn{4}{l}{ Equiangle skew (Fluent) factor range (\%) } \\
\cline { 6 - 8 } & & & $0-0.25$ & $0.25-0.5$ & $0.5-0.75$ & $0.75-1$ \\
\hline 1 & 375 & 75 & 0.86 & 39 & 60 & 1 & 0 \\
2 & 558 & 59 & 0.84 & 39 & 59 & 2 & 0 \\
3 & 1226 & 49 & 0.80 & 40 & 59 & 1 & 0 \\
4 & 1824 & 49 & 0.82 & 41 & 58 & 1 & 0 \\
\hline
\end{tabular}

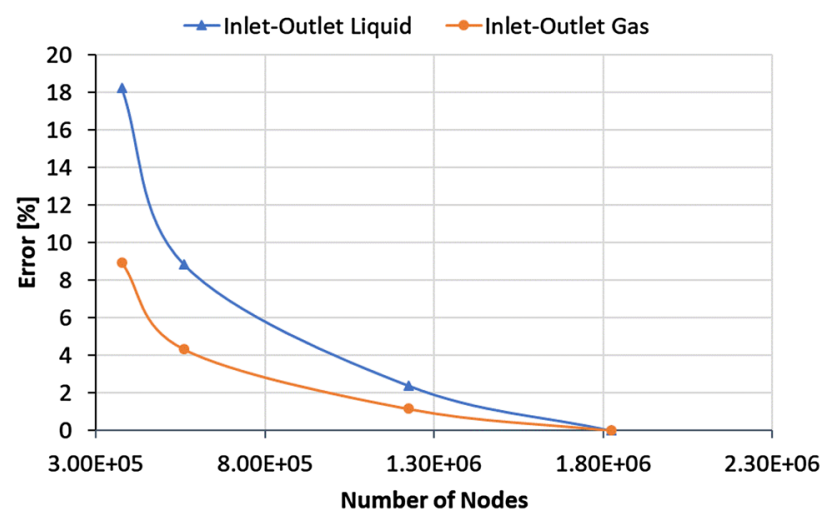

Fig. 3 Pressure difference between inlet and outlet for different number of nodes (mesh independence study)

computational effort. Four different meshes were created with an increasing number of tetrahedral elements. All meshes have an inflation layer close to the wall consisting of 10 layers (growth rate of 1.2) to accurately capture gradients of variables when close to the wall. The number of nodes in the four meshes and other mesh quality indicators are shown in Table 2.

The following values were calculated and compared between all meshes:

- Mass flow through both outlets

- Area average pressure in 13 cross-sectional planes along the geometry

- Pressure difference, delta $P$, between the inlet and the two outlets

- Velocity magnitude in 6 points. The points were located in the pipe center at the following locations: (1) inlet pipe just before the first branch, (2) elbow at exit of the first branch, (3) and (4) inlet and outlet of the third branch, and (5) and (6) inlet and outlet of the sixth branch.

The relative error of the calculated values, defined as the relative difference (in percentage) from the finest mesh, is plotted against the number of nodes in each mesh to compare the meshes. This is shown for the pressure difference between the inlet and both outlets in Fig. 3. The mesh with 1226-k elements (shown in Fig. 4) exhibited deviations less

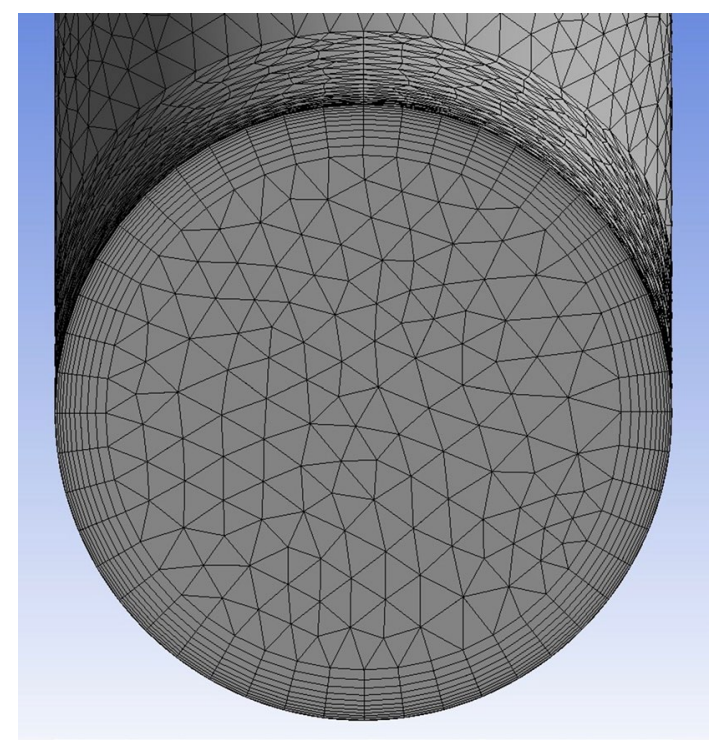

Fig. 4 Cross section of the mesh (Refsnes 2017)

than 3\% from the finest (except for the velocity in one point); thus, it was chosen as the final mesh.

The CFD model employed uses wall functions to handle the near wall region (i.e., imposing a velocity profile depending on the turbulence model chosen). Therefore, to obtain accurate results, usually the centroid of the mesh cell adjacent to the wall should be located in the log region of the boundary layer. To verify this criterion quantitatively, turbulence models often provide a suggested $\mathrm{y}^{+}$ range $\left(y^{+}\right.$is the dimensionless distance of the first node to the wall, defined by Eq. 1). For the turbulence model used in this work, $K$-epsilon, the recommended $y^{+}$range is $y^{+}<300$.

For the final mesh chosen, the thickness of the first cell close to the wall $(\Delta y)$ is $0.48 \mathrm{~mm} . y^{+}$values were estimated for both phases using Eq. 8 and velocity of $2 \mathrm{~m} / \mathrm{s}$, resulting in the initial estimates of $y_{\mathrm{g}}^{+}=240$ and $y_{\mathrm{o}}^{+}=5$.

$y^{+}=\frac{\rho u_{*} \Delta y}{\mu}$ 
where $\rho$ is density, $u_{*}$ is friction velocity, and $\mu$ is dynamic viscosity.

\section{Description of CFD simulations performed}

All simulations are performed in transient conditions with the following boundary conditions:

- Inlet mixture velocity, $U_{\text {inlet }}^{\text {mix }}=2 \mathrm{~m} / \mathrm{s}$.

- Outlet liquid $(\mathrm{OL})$ average static pressure, $P_{\mathrm{OL}}=85$ bara

A description of all simulations performed is presented in Table 3. Case 1 is a sensitivity study changing the outlet gas pressure, using nine different values with a constant inlet gas volume fraction $(\mathrm{GVF})$ of 0.3 . It was observed that a small change in this pressure ( 0.01 bara) caused an appreciable effect in the inner liquid distribution inside the separator; therefore, the change steps chosen are small.

Case 2 is a sensitivity study varying the inlet gas volume fraction. The effect of three different volume fractions is studied $(0.3,0.5,0.7)$.

In Case 3, a study on the ability of the separator to handle upstream slug flow conditions of various periods was conducted. Slug flow at the inlet was modeled by alternating with time the GVF at the inlet between primarily liquid with gas entrained $(\mathrm{GVF}=0.1)$ and primarily gas with liquid entrained (0.9). Constant boundary conditions are an inlet velocity of $2 \mathrm{~m} / \mathrm{s}$, outlet gas pressure sets to 84.95 bara, and outlet liquid pressure sets to 85 bara.

The simulation plan for Case 3 is shown in Table 4. Case 3.1 was set with 1-s-long slugs which corresponds to a 2-m-long slug, while Case 3.2 was set with 4-s-long slugs which corresponds to an 8-m-long slug.

The total simulation time for these simulations was set to 10 times the longest residence time of the two fluids inside

Table 3 Simulation plan for performance evaluation

\begin{tabular}{lll}
\hline Case & Inlet GVF & $\boldsymbol{P}_{\mathbf{O G}}$ (bara) \\
\hline Case 1 & & \\
Case 1.1 & 0.3 & 84.90 \\
Case 1.2 & & 84.91 \\
Case 1.3 & & 84.92 \\
Case 1.4 & & 84.93 \\
Case 1.5 & & 84.94 \\
Case 1.6 & & 84.95 \\
Case 1.7 & & 84.96 \\
Case 1.8 & & 84.97 \\
Case 1.9 & & 84.99 \\
Case 2 & & \\
Case 2.1 & 0.5 & 84.95 \\
Case 2.2 & 0.7 & \\
\hline
\end{tabular}

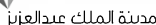

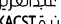

Table 4 Simulation plan for evaluation of slug handling

\begin{tabular}{lll}
\hline Case & Inlet GVF & Slug period (s) \\
\hline Case 3 & & \\
Case 3.1 & $0.1 / 0.9$ & 2 \\
Case 3.2 & & 8 \\
\hline
\end{tabular}

the separator. Approximate residence times are found by dividing the distance travelled by the velocity.

Figure 5 shows the assumed travel path through the separator in colors. The green line applies for both fluids, while the red line applies for gas and the blue line for oil after the splitting point. The velocity is assumed to be equal to the inlet velocity of $2 \mathrm{~m} / \mathrm{s}$ at the green line and $1 \mathrm{~m} / \mathrm{s}$ at the red and blue line after the flow is split in two. A gas particle travels 5.6 meters and an oil particle travels 5 meters from inlet to outlet. Thus, the gas and oil residence times are 4.5 and $3.9 \mathrm{~s}$. All transient simulations are run for $45 \mathrm{~s}$, which is long enough for the gas to flow from inlet to outlet 10 times.

Gas carry under (GCU) and liquid carry-over (LCO) are measures of the amount of gas escaping through the liquid outlet and liquid escaping through the gas outlet, respectively, which are calculated using Eqs. 9 and 10. Oil and gas separation efficiencies were also estimated, which are equal to 1-GCU and 1-LCO, respectively:

$\mathrm{LCO}=\frac{m_{\mathrm{OG}}^{\mathrm{o}}}{m_{\mathrm{OG}}^{\mathrm{o}}+m_{\mathrm{OL}}^{\mathrm{o}}}$

$\mathrm{GCU}=\frac{m_{\mathrm{OL}}^{\mathrm{g}}}{m_{\mathrm{OG}}^{\mathrm{g}}+m_{\mathrm{OL}}^{g}}$

where $m_{\mathrm{OG}}^{\mathrm{g}}$ and $m_{\mathrm{OL}}^{\mathrm{g}}$ are the mass flow rates of gas through outlet gas and outlet liquid and $m_{\mathrm{OG}}^{\mathrm{o}}$ and $m_{\mathrm{OL}}^{\mathrm{o}}$ are the mass flow rates of oil through outlet gas and outlet liquid.

Convergence criteria for the simulations are:

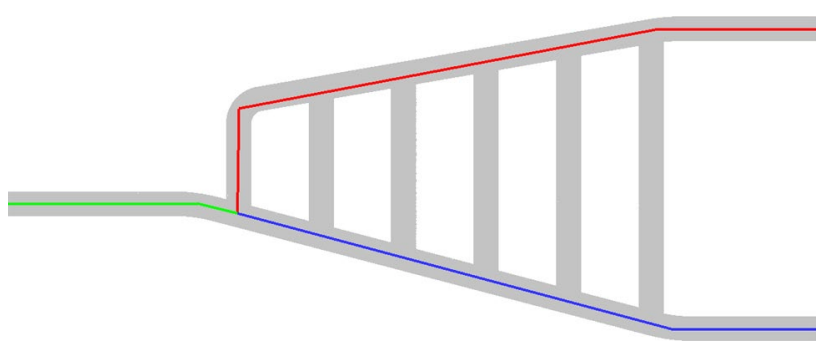

Fig. 5 Travel flow path through the separator 
- Root mean square (RMS) residuals below a value of $5 \mathrm{E}-5$

- Maximum (MAX) residuals below a value of $1 \mathrm{E}-3$

- Imbalances below $1 \%$

\section{Results}

\section{Effect of the outlet pressure on separation performance}

Small variations in outlet gas pressure have a big effect on the liquid level in the vertical pipes as shown in Fig. 6, where $\Delta P_{\text {outlets }}=P_{\mathrm{OL}}-P_{\mathrm{OG}}$. The results show a liquid level which decreases with a decreasing $\Delta P_{\text {outlets }}$.

The gas outlet (OG) pressure has a significant effect on the flow distributions in the branches (vertical pipes). For an OG pressure between 84.93 bara and 84.95 bara, all gas flows up the first branch, while the oil flows in the lower part of the separator as shown in Fig. 6. Lower OG pressures cause some oil to flow with the gas up the first branch and flow down some of the next branches. For example, for $P_{\mathrm{OG}}=84.92$ bara (Fig. 6b) the liquid flows up in the first branch and flows down in branches 2, 3, and 4. For $P_{\mathrm{OG}}=84.90$ bara (Fig. 6a), the liquid flows up in the first branch and flows down in branches 2, 3, 4, 5, and 6. In these cases, most of the downward flow of liquid occurs through the last branch.
An increase in OG pressure above 84.95 bara (Fig. 6d) leads to gas flowing upwards through other branches (2-6). Gas recirculation is seen for these cases, where the gas flows back down through the branches to the left of the branch that has upward flow. Thus, $P_{\mathrm{OG}}=84.96$ bara results in upward flow through branch 3 and downward flow through branches 1 and 2 , and $P_{\mathrm{OG}}=84.97$ bara (Fig. 6e) causes upward flow through branch 5 and downward flow through branches 1-4 while upward flow through the last branch and downward flow through branches $1-5$ are detected for $P_{\mathrm{OG}}=84.99$ bara (Fig. 6f).

LCO and GCU are plotted versus $\Delta P_{\text {outlets }}\left(P_{\mathrm{OL}}-P_{\mathrm{OG}}\right)$ in Fig. 7 ( $\Delta P_{\text {outlets }}=0.1$ bar is equal to a $P_{\mathrm{OG}}$ of 84.99 bara $)$.

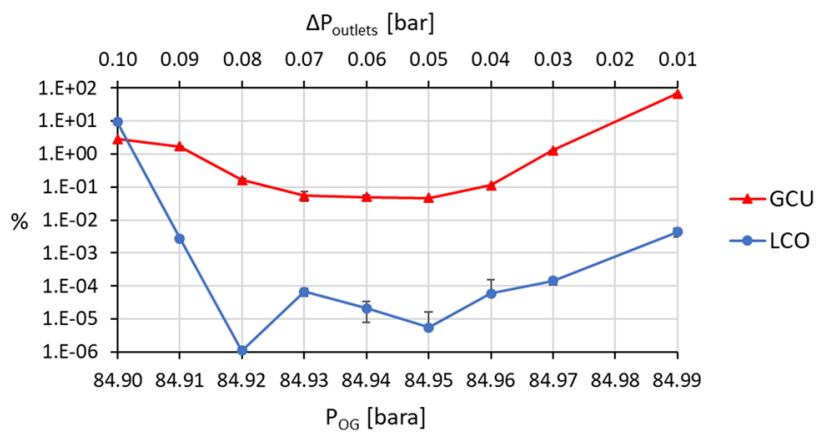

Fig. 7 Comparison curve of LCO and GCU with respect to the gas outlet pressure $\left(\mathrm{P}_{\mathrm{OG}}\right)$
Fig. 6 GVF plot of different outlet gas pressures. Note Screenshots are made at the end of the total simulation time

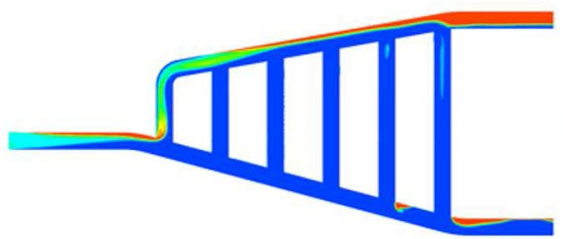

(a) $P_{O G}=84.90 \mathrm{bara}$

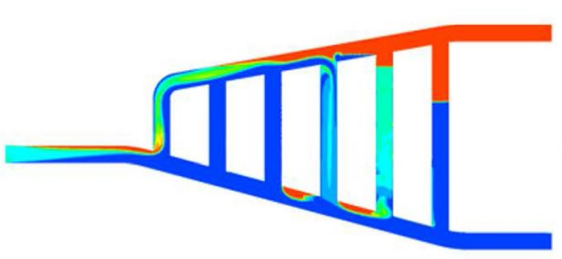

(b) $P_{O G}=84.92$ bara

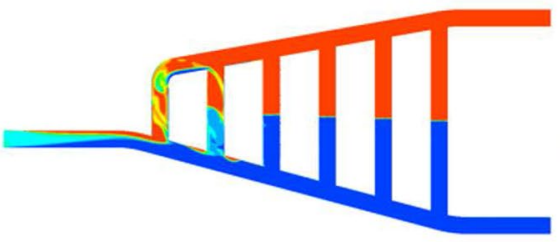

(c) $P_{O G}=84.94 \mathrm{bara}$

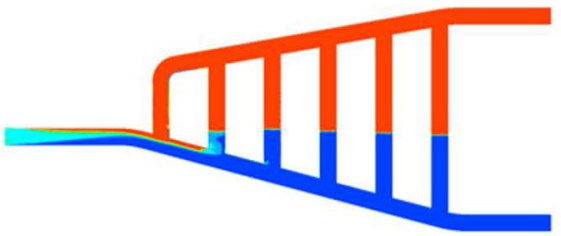

(d) $P_{O G}=84.95 \mathrm{bara}$

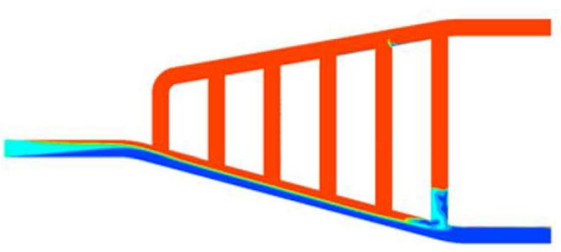

(e) $P_{O G}=84.97$ bara

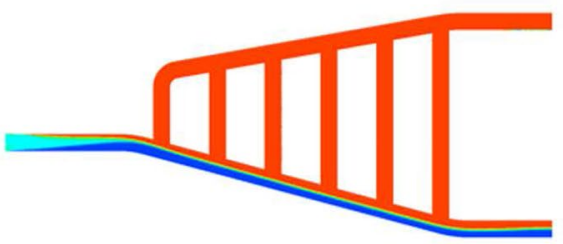

(f) $P_{O G}=84.99 \mathrm{bara}$

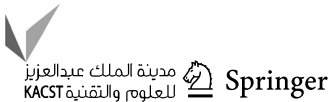


Error bars are plotted, but most of them are too small to show on the plot (the error values are the standard deviation of the collection of transient results). Low values of LCO are seen for all OG pressures except for 84.90 bara, which results in an LCO of $9.26 \%$. This increased LCO is due to a higher liquid level, which reaches part of the gas outlet (as shown in Fig. 6a). Further decreasing the OG pressure will lead to an increasing LCO.

The increased GCU for OG pressures below 84.92 bara is due to the change in the flow distribution. The oil moves up with the gas through the first branch and down the last two vertical pipes for these pressures. This results in gas being carried with the oil down the last branches and out of the liquid outlet.

A decreased separation performance is seen for OG pressures above 84.96 bara, in which $P_{\mathrm{OG}}=84.97$ bara results in a GCU of $1.27 \%$, while $P_{\mathrm{OG}}=84.99$ bara results in a GCU of $67.39 \%$. This is because the gas starts to flow together with the oil in the oil-collecting pipe at the bottom, as shown in (Fig. 6e) and (Fig. 6f), respectively. No significant effect is observed on the LCO. In general, values of $\Delta P_{\text {outlets }}\left(P_{\mathrm{OL}}-P_{\mathrm{OL}}\right)$ between 0.03 and 0.09 bar result in acceptable gas and oil separation performances.

\section{Impact of the inlet GVF on separation performance}

Varying inlet GVFs between 0.3 and 0.7 does not have an effect on the LCO or the GCU, nor on the liquid height in the separator as shown in Fig. 8.

\section{CFD simulations for evaluation of slug handling}

An inlet condition with 2-m-long liquid slugs (2-s slug period) creates a cyclic oscillation of the liquid level in the vertical branches. The number of branches filled with gas changes in time from 1 (when an oil slug enters the separator) to 3 (when a gas pocket enters the separator).
Fig. 8 GVF plot of different outlet gas pressures. Note Screenshots are made at the end of the total simulation time

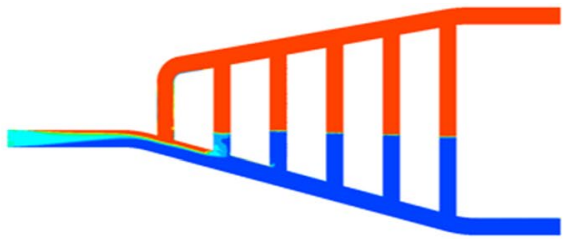

(a) Inlet GVF $=0.3$

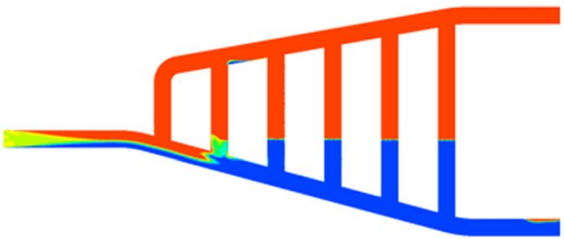

(a) Inlet GVF $=0.7$
Fig. 9 GVF plots showing the transient behavior of the liquid level during a slug flow

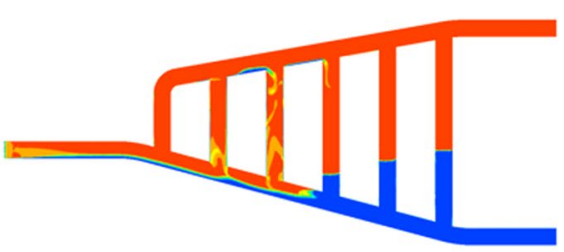

(a) At time $=40 s$-oil slug enters the separator

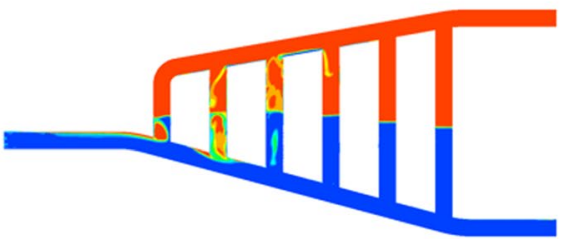

(b) At time $=42 \mathrm{~s}$

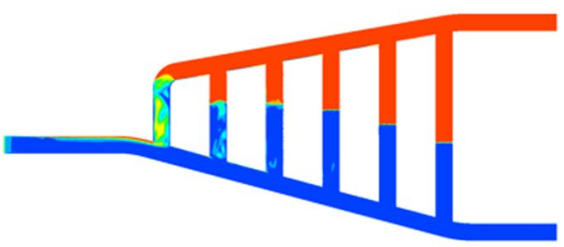

(c) At time $=44 s-$ gas pocket enters the separator

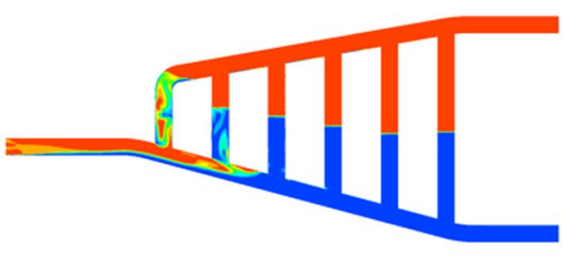

(d) At time $=45 \mathrm{~s}$

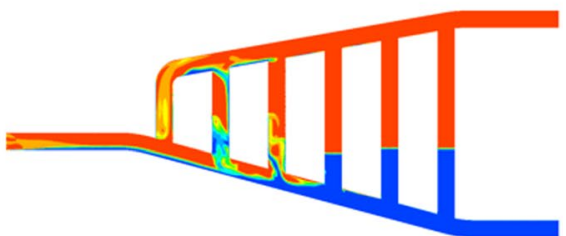

(e) At time $=46 \mathrm{~s}$

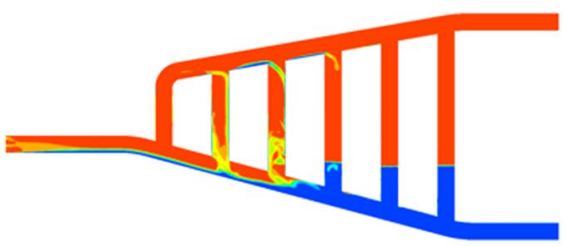

(f) At time $=47 \mathrm{~s}$ 


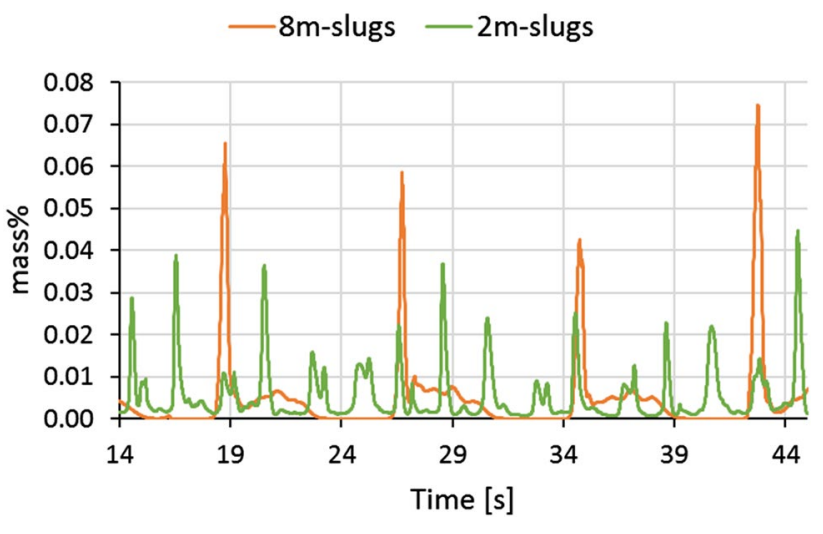

Fig. 10 Mass \% gas flowing through OL for 8- and 2-m slugs (Case 3.1 and Case 3.2)

A similar liquid level oscillation but of higher magnitude is seen for 8-m-long slugs (Case 3.2), as shown in Fig. 9. The highest change in liquid height occurs during the first seconds of the arrival of a liquid slug or a gas pocket, and then, it slowly stabilizes until the next slug/pocket arrives. The stabilization of the liquid height at the end of a cycle happens because the flow starts to reverse at the outlets, which are immediately partially or fully closed in the simulations. When an oil slug arrives, the gas outlet is closed due to the low amounts of gas in the separator; likewise, when a gas pocket arrives, the oil outlet is partially closed.

The inlet pressure fluctuates in time but stays between 84.95 and 85 bara. Keeping the pressure constant at the outlets results in back flow at the liquid outlet for the low liquid level during gas-dominated feeds. It also results in back flow at the gas outlet for the high liquid level during oil slugs. No back flow is allowed through the outlets, which is why a wall is placed automatically at the cross-sectional area by the simulation program. This did not happen in the case with shorter (2-m) slugs.

The percent of gas mass flow flowing through the liquid outlet (OL) with respect to the gas mass flow at the gas outlet was computed and is plotted in Fig. 10 versus time for 2-m and 8 -m slug lengths. The gas mass flow percentage fluctuated according to the slug cycles. The average gas mass flow percent for Cases 3.1 and 3.2 is low, $0.0055 \pm 0.0068 \%$ and $0.0045 \pm 0.0096 \%$, respectively. Thus, the separation efficiencies remain high even when the separator is subjected to slug flow.

\section{Conclusions and recommendations}

- An inhomogeneous model with continuous-continuous phases considering buoyancy and drag showed acceptable convergence and physically logic results of oil-gas segregation inside the multi-branch pipe separator.
- For operating conditions that had high separation efficiency, gas-liquid separation occurs only through some of the vertical branches closer to the inlet while a static liquid level is established in the branches closer to the outlet. This static liquid level is depended on the outlet pressure set at the gas and oil outlet.

- If the pressure difference between the liquid and gas outlets is changed to values below 0.03 bar, there will be significant gas carry under. If the pressure difference between the liquid and gas outlets is changed to values above 0.09 bar, there will be a significant liquid carryover and gas carry under. Translating these pressure differences to liquid heights, this means that the separation efficiency is optimal when the liquid level in the separator is in the range $18-56 \%$ of the total length of the last vertical branch.

- The liquid level in the separator was not affected significantly by the value of the inlet volume fractions in the range $0.3-0.7$ when using a constant inlet flow velocity.

- The multi-branch separator showed well slug-handling abilities and high separation performances for the studied slug flow conditions. The liquid level of the static branches oscillated to compensate for the variations in the inlet oil and gas rates. For long liquid slugs, it is necessary to install check valves at the outlets of the separator to avoid back flow.

Acknowledgements This work was carried out as a part of SUBPRO, a Research-based Innovation Centre within Subsea Production and Processing. The authors gratefully acknowledge the financial support from SUBPRO, which is financed by the Research Council of Norway, major industry partners, and NTNU.

Open Access This article is distributed under the terms of the Creative Commons Attribution 4.0 International License (http://creativeco mmons.org/licenses/by/4.0/), which permits unrestricted use, distribution, and reproduction in any medium, provided you give appropriate credit to the original author(s) and the source, provide a link to the Creative Commons license, and indicate if changes were made.

\section{References}

Afolabi EA, Lee JGM (2014) An Eulerian-Eulerian CFD simulation of air-water flow in a pipe separator. J Comput Multiph Flows 6:133-149

Barth TJ, Jesperson DC (1989) The design and application of upwind schemes on unstructured meshes. AIAA paper 89-0366

Beggs HD, Robinson JR (1975) Estimating the viscosity of crude oil systems. J Pet Technolgy 27:1140-1141

Da Mota FRM, Pagano DJ (2014) Simulation and experimental study of phase segregation in helical pipes: a new method for flow conditioning. Flow Meas Instrum 35:99-108

Euphemio M, Oliveira R, Nunes G, Capela C, Ferreira L (2007) Subsea oil/water separation of heavy oil: overview of the main

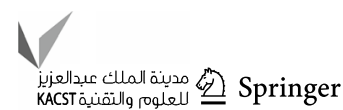


challenges for the Marlim field-campos basin. In: Offshore technology conference

Ghaffarkhah A, Shahrabi MA, Moraveji MK (2018) 3D computationalfluid-dynamics modeling of horizontal three-phase separators: an approach for estimating the optimal dimensions. In: SPE production and operations. https://doi.org/10.2118/189990-PA

Ghaffarkhah A, Dijvejin ZA, Shahrabi MA, Moraveji MK, Mostofi M (2019) Coupling of CFD and semiempirical methods for designing three-phase condensate separator: case study and experimental validation. J Pet Explor Prod Technol 8:353-352

Gramme PE, Lie GH (2011) Pipe separator inlet 11/886159. U.S. patent number 7901492 B2

Lee AL, Gonzalez MH, Eakin BE (1966) The viscosity of natural gases. J Pet Technol 18:997-1000

Monesi A, Pinelli M, Verga C (2013) Slug catcher two-phase flow modeling and numerical simulations. In: Offshore technology conference

Orlowski R, Euphemio MLL, Euphemio ML, Andrade CA, Guedes F, Tosta Da Silva LC, Pestana RG, De Cerqueira G, Lourenço I, Pivari A, Witka A, Folhadella H, Pacheco L, Kronemberger S, Vilela J (2012) Marlim 3 phase subsea separation system—challenges and solutions for the subsea separation station to cope with process requirements. In: Offshore technology conference

Refsnes HS (2017) Computational fluid dynamics (CFD) simulation of the harp separator. Norwegian University of Science and Technology, Trondheim

Refsnes HS (2018) Performance evaluation of a multi-branch liquidgas pipe separator using computational fluid dynamics. Master, Norwegian University of Science and Technology

Sagatun SI, Gramme P, Lie G, Horgen OJ, Ruud T, Storvik M (2008) The pipe separator-simulations and experimental results. In: Offshore technology conference

Standing MB (1947) A pressure-volume-temperature correlation for mixtures of California oils and gases. In: Drilling and production practice, New York, American Petroleum Institute

Publisher's Note Springer Nature remains neutral with regard to jurisdictional claims in published maps and institutional affiliations. 